\title{
ONLINE RESOURCES FOR LANGUAGE EDUCATION DURING PANDEMIC LOCKDOWN
}

\author{
Tatyana Yu. Guryanova1, Elena N. Ivanova², Lilia A. Metelkova ${ }^{3}$, Kristina V. \\ Fadeeva $^{4}$, Andrey G. Firsov ${ }^{5}$, Elena L. Zaitseva ${ }^{6 *}$ \\ 1Associate Prof., The Ulianov Chuvash State University, RUSSIA, vgurtat@yandex.ru \\ ${ }^{2}$ Associate Prof., The Chuvash State Agrarian University, RUSSIA, ien161110@mail.ru \\ ${ }^{3}$ Associate Prof., Moscow State University of Civil Engineering (National Research University), \\ RUSSIA, lilia.metelkova@gmail.com \\ ${ }^{4}$ Associate Prof., Cheboksary Institute (branch) of Moscow Polytechnic University, RUSSIA, \\ cristinafadeeva@mail.ru \\ ${ }^{5}$ Associate Prof., Emperor Alexander I St. Petersburg State Transport University, RUSSIA, \\ agfirsov@mail.ru \\ ${ }^{6}$ Associate Prof., The Ulianov Chuvash State University, RUSSIA, 917elena@mail.ru \\ ${ }^{*}$ Corresponding author
}

\begin{abstract}
The article is the author's take on up-to-day technologies in forming the foreign language competence of the future lawyers. Educational process of law students in a foreign language cannot be carried out without a proper system of monitoring the development of communication skills and abilities. As a result of using multimedia technologies, both the teacher and the student get the opportunity to pay attention to the existing gaps in communication skills and adjust their speech activity accordingly. From the point of view of the competence approach, the goal of teaching future lawyers a foreign language is to form their communicative competence, which includes the student's ability to correctly and argumentatively maintain oral and written speech The control of using multimedia technologies provides the necessary information for analysis and making appropriate changes in the organization of the educational process. Multimedia has become one of the leading learning tools in the period of distance learning. Multimedia is a technology that combines information (data), sound, animation, and graphics. Using modern appliances have made it possible to qualitatively change the control over students' activities, while providing flexibility in managing the educational process. Using the information resources of the Internet allows integrating them into the educational process to more effectively solve a number of didactic tasks in a practical lesson. The use of computer presentations in the classroom allows to introduce new material in the most exciting way, the principle of visibility is implemented, which contributes to the solid assimilation of information.
\end{abstract}

Keywords: multimedia technologies, professional language education, distance learning, law student, communication skills, Zoom, information, speaking, pandemic lockdown, computer communication.

\section{INTRODUCTION}

The social demand for foreign language training of lawyers entails a number of fundamental changes and additions to the education system in law schools. The importance of studying foreign languages for business 
and professional contacts, including international ones, to maintain democratic stability, employment and mobility of people in the world community is emphasized in the legal instruments of the Council of Europe (2001), the Federal law "On education", Federal law "On higher and postgraduate professional education" (1996), National doctrine of education in the Russian Federation for the period up to 2025 (2000). Language education should be aimed at mastering a foreign language as a means of communication in real life situations, including in professional activities in direct contact with native speakers of another language. From the point of view of the competence approach, the goal of teaching future lawyers a foreign language is to form their communicative competence, which includes the student's ability to correctly and argumentatively maintain oral and written speech, carry out communicative activities on a tolerant basis, master the basics of business correspondence, be able to negotiate in a foreign language, have a proper speech culture, which generally determines the successful solution of problems in a multicultural environment (1, p. 118-121).

Deep study of a foreign language in the framework of professional training of students should play a crucial role in the development of multicultural competence among law students and employees of internal affairs institutions. At various stages of formation of professional orientation of the identity of future lawyers, it is important to consolidate the acquired knowledge in the field of foreign cultures and skills and the ability to exercise constructive interaction with representatives of different cultural groups, leading to understanding, to empathy, to assist others not just favorable for the individual conditions, but in more complex situations when the legal profession representative must make some moral and strong-willed efforts (2, p. 201-204). In this regard, there are corresponding changes in the practice of teaching foreign languages. The today-society is being informatized and the relevance of using multimedia technologies in the educational process is increasing. Due to the dynamic progress of information technologies, there is a need to change the educational process, clarify the goals and objectives in the development of new technologies, and introduce more effective teaching methods and tools. Multimedia has become one of the leading learning tools in the period of distance learning. Multimedia is a technology that combines information (data), sound, animation, and graphics. A multimedia product is an interactive software that can include music and speech accompaniment, visual range, animation, graphic images and slides, databases, text, etc.

It is known that at least $70 \%$ of the information a person receives visually, so the use of multimedia when teaching foreign languages can be very effective. In modern society, the role of foreign languages is increasing. Knowledge of a foreign language gives law students the opportunity to join the world culture, use the resources of the global Internet in their professional activities, as well as work with information and communication technologies and multimedia learning tools.

\section{DISCUSSION}

The purpose of teaching a foreign language is to provide students with practical knowledge of a foreign language. The teacher's task is to activate the activity of each student in the learning process, to create situations for their creative activity. The main purpose of teaching a foreign language to students of legal professions is to educate a person who is willing and able to communicate, people who are willing and able to provide self-education. In the future, they can use their knowledge in their work, including abroad. This implies not only a high level of foreign language proficiency, but also certain personality traits: sociability, lack of a language barrier, knowledge of international etiquette, a broad outlook, and the ability to "present" yourself. To achieve all these goals, effective assistance to the teacher in teaching a foreign language is provided by the use of computer technologies, Internet resources and presentations. All this is most often referred to as multimedia technologies.

Currently, the computer, multimedia technologies and the global Internet affect the education system, causing significant changes in the content and methods of teaching foreign languages. The importance of using distance learning technologies in education is analyzed in detail in the works of scientists such as A. A. Andreev, E. S. Polat, A. E. Petrov, V. I. Soldatkin, V. P. Tikhomirov, A.V. Khutorsky, V. D. Shadrikov, V. A. Shapovalov. Their views reflect a wide range of ideas about the essence and content of distance education technologies, the features of their use in the educational process. Distance learning as a social phenomenon is actively developing in the modern world. Distance learning is a new form that previously organically complemented full-time, part-time and evening forms of education, but completely replaced them during the global epidemic. A number of authors (I. V. Robert, O. V. Vitchenko, E. V. Nikulicheva, etc.) define the concept of "distance learning" as a specially organized purposeful process of interaction between teachers and students, aimed at mastering knowledge, skills and abilities, forming a worldview, developing mental abilities, potential opportunities for students to develop and consolidate self-education skills in accordance with the learning objectives. Other authors define distance learning as ordered interaction of the teacher with 
students, aimed at achieving a goal or as a certain process of cognition, controlled by the teacher. In the content of these concepts, the key concepts are process and interaction, and in this context, distance learning is considered a two-way activity.

In the context of the COVID-19 pandemic, online learning has developed rapidly. Almost all Russian universities switched to distance learning from March 16, 2020. During the March-June 2020 pandemic lockdown, University teachers faced the problem of finding a new pedagogical tool. Skype, Zoom, and Discord programs have made it possible to qualitatively change the control over students' activities, while providing flexibility in managing the educational process. The use of multimedia technologies allows you to make an informed choice of the best training option.

Distance learning at Chuvash State University named after I. N. Ulyanov is carried out on such platforms as Webinar platform of Chuvash State University (tt.chuvsu.ru/webinar), Webinar.ru, Zoom, Skype (in video conference mode), Discord (in video conference mode), RUNNet. The development of local networks allows you to support the process of teaching law students a foreign language at the proper level. Today, all teachers of the university conduct classes online, without experiencing difficulties and fears. Professionals note the convenience of using the Skype program for individual consultations and paired classes, the Zoom and Discord service platforms for group classes. At the very beginning of distance learning (March-April 2020) students had difficulties in connecting, activating the tools (sound, camera,) lack of audibility, inability to turn on a web camera, then with the help of Screencast-o-matic, Bandicam or Zoom programs, a teacher could record a detailed video instruction for students with a voice explanation. Before starting a class, a teacher could make a test call to students on the platform selected for the class. During a group session the teacher periodically accessed the platform from different devices (computer, tablet, phone) as a student to see what the students see and understand the problems that arise.

Teachers have to highly premeditate the form of displaying the educational text: on the screen, on the blackboard, in the slide-show view from PowerPoint or in PDF printouts, as well as the volume of the text. A text can be sent to the students by e-mail in advance in order for students to print out the text. They can be provided with a link to the desired material as well.

To teach reading online, teachers use the distance learning technical resources, such as CuePrompter, Online dictionary, Scribe Rewordify.

Our teachers have a great choice of tools when at Business Correspondence Course both for online classes and for independent study of students:

- SpellingCity - a program for mastering vocabulary, which is an interesting spelling practice. Automation of tests helps to save teachers' time, so that students can improve their spelling independently during the game activity;

- Storybird - an online service for creating your own stories using illustrations and text messages;

- Ozdic - an online dictionary that allows you to search for common phrases, a useful resource for vocabulary development;

- Bubbl.us - a web-based tool that allows you to structure project ideas in the form of a diagram;

- Book Creator - a tool for creating e-books on iPad, Chromebook and in the Internet;

- Make Beliefs Comix - the ability to create comics that develop the imagination, teach writing, storytelling, literature analysis;

- Write \& Improve - a free service for instant automatic verification of written tasks (3).

When using a computer, verbal communication activities should be considered as communication between students and teachers in a virtual classroom in real time. The addition is the use of e-mail and information networks. One of the most important factors for the success of distance learning of a foreign language is the creation of a speech partnership in the classroom. In our opinion, the control functions depend on its goals and objectives. By its means, by its control tasks, it should help to implement the training tasks, and therefore its purpose should be adequate to the training tasks. The main task of monitoring is to objectively determine the level of proficiency in language material and speech skills at a certain stage. The use of multimedia tools helps to implement a person - oriented approach to learning, provides individualization and differentiation, taking into account the characteristics of students, their level of training, and aptitudes.

The leading component of the content of foreign language teaching is teaching various types of activity speaking, listenening, reading, and writing. When learning to listen, each student gets the opportunity to hear 
a foreign language. When learning to speak, each student can pronounce phrases in English into a microphone. When studying grammar, each student can perform grammatical exercises by solving crosswords, chainwords, searching for words, and performing game exercises. In sing a computer in the educational process its teaching function is emphasized; the computer is a tool that organizes and manages students' independent work, especially in training work with language and speech material.

In addition, it is difficult to overestimate the role of the computer as a means of exercising control over the activities of students by the teacher, as well as as a means of forming and improving self-control. Control was carried out during practical classes in a foreign language, independent work of students and in the process of performing additional individual tasks remotely using Internet technologies. Law students get acquainted with speech patterns, study authentic texts about the professional activities of lawyers both in Russia and in the countries of the language being studied. For the preparation of texts for extracurricular reading, among many others, the following manuals made by the authors of this article are offered: "Country study: law and order" - this is a reading anthology containing authentic texts on country studies and original texts borrowed from Anglo - American police literature of particular professional interest;

"English through cultures" - a reading textbook developed by us, containing authentic texts not only about the culture of the peoples of England and the United States, but also other countries of the world, about various types of cultural intersections, as well as a set of tasks, questions for discussion, role-playing games and situational tasks aimed at forming a communicative professional competence. In difficult cases, the computer allows the student to get the necessary information of a reference nature in a short period of time, to show "keys " for the successful solution of the task.

\section{CONCLUSION}

Using the information resources of the Internet allows integrating them into the educational process to more effectively solve a number of didactic tasks in a practical lesson: to form reading skills and abilities, directly using the materials of the network of varying degrees of complexity; improve listening skills based on authentic audio texts on the Internet; improve the skills of monologue and dialogical utterance based on a problematic discussion of the materials presented by the teacher or one of the students; fill up students' vocabulary, both active and passive, with the vocabulary of a modern foreign language; get acquainted with cultural knowledge, including speech etiquette, features of speech behavior of different peoples in the context of communication, features of culture and traditions of the country of the language being studied. Creating multimedia presentations is also optimal. The use of computer presentations in the classroom allows to introduce new material in the most exciting way, the principle of visibility is implemented, which contributes to the solid assimilation of information. Independent creative work of students to create computer presentations is the best way to expand the stock of active vocabulary.

Properly organized remote work with students can contribute to the growth of their cognitive and communicative interest, which in turn will help to activate and expand the opportunities for independent work of students to master a foreign language, both in practical classes and outside of school hours.

\section{REFERENCE LIST}

1. Guryanova, T. Yu., Gushchin, V. A. (2014). Potential of the discipline "Foreign language" for the formation of multicultural competence of students / Cheboksary Coorperative Institute of Russian Cooperative Institute. № 3 (17). P. 118-121.

2. Gutieva, I. G. Extremism among the young (2014). Gaps in Russian Legislation. No. 5. P. $201-204$.

3. Tips for new online teachers of English. Available at: https://www.futurelearn.com/ courses/online-tutoring/ (accessed: 22.11.2020). 